Helgoländer wiss. Meeresunters. 32, 436-443 (1979)

\title{
Meiofauna extraction efficiency by a modified Oostenbrink apparatus
}

\author{
A. H. FRICKE \\ Council for Scientific and Industrial Research, c/o Department of Oceanography, \\ University of Cape Town; Rondebosch, 7700, South Africa
}

\begin{abstract}
A semi-automatic method for the extraction of soil nematodes (Oostenbrink, 1960) was modified for the separation of psammolittorine meiofauna from routine samples collected during a marine pollution monitoring programme. This method was compared with Elmgren's (1976) decantation technique. The two procedures used did not differ significantly in terms of extraction efficiency. They were applied to samples containing nematodes and harpacticoid copepods of known numbers in medium-fine and coarse sand, using fresh water and sea water as extraction media. Losses within the apparatus were found to be negligible. By $2 \times 2 \times 2$ factorial analysis, which was used to separate the effects of methods and treatments, nonsignificant differences for nematode recovery were obtained; harpacticoids, however, were less efficiently recovered by the Oostenbrink method using sea water. The Oostenbrink flotation method took 9 to 12 min per sample, caused no or only little damage to the fauna and gave consistent results with different operators.
\end{abstract}

\section{INTRODUCTION}

There are numerous methods for the separation of interstitial fauna from sediments; most are based on variations of decantation and flotation (e. g. Cobb, 1924/25; Caveness $\&$ Jensen, 1955) and a few on the principle of changing the intensity of environmental factors such as the sea-water ice method (Uhlig, 1964) and warm-water elutriation. Separation by washing and sieving through graded screens was employed by Ankar \& Elmgren (1976) and Dybern et al. (1976) for the separation of meiofauna from benthic samples. Some of the older methods were discussed in some detail by Oostenbrink (1960), mainly from the viewpoint of the plant pathologist, while marine biological aspects were considered by Uhlig et al. (1973), who made a comparison of methods employed for meiofauna separation in order to evaluate their advantages and shortcomings. The present paper assesses the Oostenbrink flotation method, an extraction technique not mentioned by Uhlig et al. (1973). The results were compared with the decantation method practised by Elmgren (1976). It ranks high in terms of total separation percentage of meiofauna, although it is considered time consuming.

For pollution studies we required a method effective in coping with a large number of field samples at a given time, being both gentle in use and less affected by variations introduced by the operator. Therefore, the Oostenbrink flotation principle, which depends on differences in the settling velocity between organic and sediment particles, seemed a 
promising approach. This method appeared to extract soft fauna efficiently as shown during initial trials.

\section{MATERIALS AND METHODS}

Oostenbrink flotation method. The apparatus employed in this experiment is shown in Figure 1. It is similar to the one described by Oostenbrink (1960) of an earlier model by the same author but has a trap for larger sediment samples (i. e. above $100 \mathrm{ml}$ ). Both fresh water and sea water were used as extraction media. One hundred fixed nematodes (largely Axonolaimidae, Leptosomatidae, Desmodoridae and Oncholaimidae) and harpacticoid copepods (Phyllopodopsyllus) were hand-picked from a natural beach sample and gently but thoroughly mixed into $100 \mathrm{ml}$ each of medium and coarse sand. The sand originated from the same locality as the fauna and was cleared of all organisms before use. Using known numbers of animals avoided the need for normalising the results. Five replicates each were prepared for the methods and treatments. The experimental mixtures were gently washed into the separator through a $1-\mathrm{mm}$ screen after the apparatus had filled up with water to the level of the spreader (Fig 1, N). A row of small holes pointing obliquely upward at the tip of the nozzle produced a jet of water keeping the organisms in suspension, while the sediment particles sank into the trap (Fig. 1, E). A flow rate of 11 per min was adjusted and found to be "safe" in effectively avoiding fauna losses, while at the same time allowing the sediment to sink out of the water column in a short time.

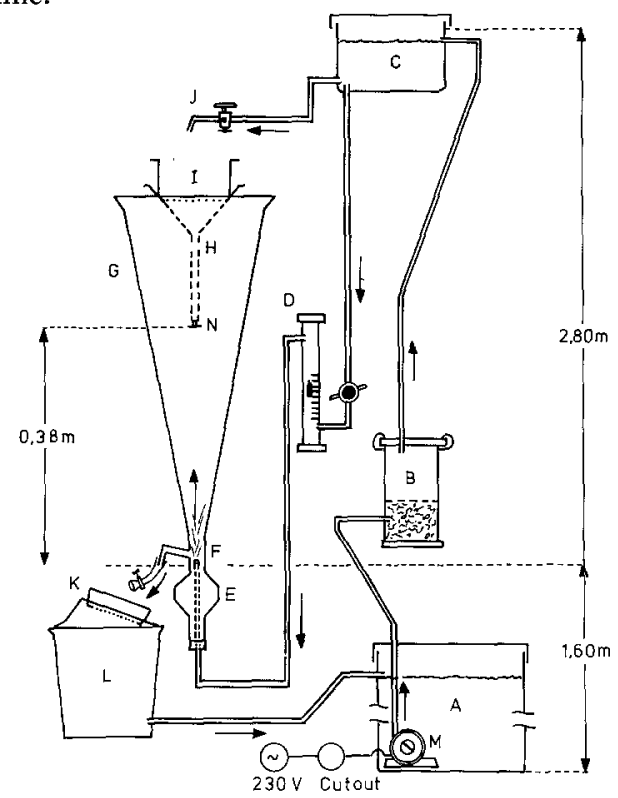

Fig. 1: Diagrammatic sketch and flow diagram of modified Oostenbrink (1960) apparatus used in the experiment (not to scale). (A) Main water-storage tank, (B) glass-wool filter, (C) head tank supplying water to nozzle (F) and tap (J), (D) adjustable flowmeter, (E) sediment trap, (F) nozzle, (G) separating funnel, $(\mathrm{H})$ long stem funnel, (I) primary screen $(1 \mathrm{~mm}$ mesh), (J) tap for washing in sample, (K) final screen $(45 \mu \mathrm{m}),(\mathrm{L})$ bucket with return hose to main tank, (M) submersible pump, (N) spreader 
Several minutes were allowed for separation, while water continued to be injected into the funnel until it rose to the body of funnel (Fig. 1, H). The accumulated volume of water was drained through the side arm into a $45-\mu \mathrm{m}$ sieve supported by a bucket leading the supernatant back into the lower reservoir via a hose. A small beaker catching the jet of draining water from the side arm is helpful in preventing organisms becoming impacted on the sieve. Fauna accidentally lost is caught by a filter filled with glass wool (Fig. 1, B). Earth leakage protection is a safe-guard when using a mains operated submersible pump.

Although the dimensions of the apparatus are not critical, a few details warrant emphasis: (a) the slope of the separating funnel should not be less than 4:1 (Oostenbrink, 1960), i. e. a minimum water column is necessary for efficient separation; (b) the nozzle holes must not be below the opening of the side arm; (c) the trap should easily accommodate the volume of sand in a particular sample; (d) water must flow as long as organisms are in the apparatus. Excessive flow tends to accumulate sediment on the final screen; (e) samples containing much silt are unsuitable for separation by this method; (f) stainless steel (marine specification) was found to be an eminently suitable material for constructing the separator.

Decantation. Extraction of fauna by this method was performed on a set of similar replicate samples in a $500-\mathrm{ml}$ beaker using $200 \mathrm{ml}$ aliquots of water, while lightly stirring the sediment. A few seconds were allowed for settling, before decanting the supernatant into a $45-\mu \mathrm{m}$ sieve. The sediment was not split into size fractions (i. e. above and below $1 \mathrm{~mm}$ grain size) but processed as a whole.

C o u n ing of organ is $\mathrm{ms}$. The extracted fauna were counted in a $10 \times 8 \mathrm{~cm}$ gridded perspex dish with sloping sides. This facilitated recognition of animals lying close to the edge. The sample was lightly stained with rose-bengal and examined under a dissecting microscope on an X-Y examining frame. A similar method of in situ counting was employed by McIntyre as reported by Uhlig et al. (1973).

\section{RESULTS}

Representative portions of $2.5 \mathrm{~g}$ (the quantity required by our hydraulic method) of the experimental sediments were processed in a settling column according to Flemming \& Thum (1977). Sediment B stems from a moderately sheltered beach, with grains of translucent quartz and milky felspar in about equal quantities. Some shell material, blades of mica and urchin spines were present. The sand appeared moderately sorted and of medium fineness. A computer plot of phi-values vs. frequency percent is shown in Figure 2.

The size distribution is polymodal and difficult to characterize (Flemming, pers. comm.). Essential moment measures are also given. Sediment A consists of well rounded quartz grains and little else. The sediment is very well sorted, coarse and has a unimodal size distribution (Fig. 3).

The results of checks of the sediment trap are given in Table 1. Except for replicate 5, which also had the fewest animals, the percentages of faunal losses are insignificant. Naturally, losses of low initial numbers (Polychaetes: replicate 1; Turbellaria: replicate 5) give a distorted impression. 
The apparatus cannot extract live meiofauna efficiently. Results of an experiment on recovery of live meiofauna are presented in Table 2 . The samples were subsequently fixed and extracted once more for comparison. Further, a list of data of methods and treatments is given in Table 3 as well as relevant basic statistics.

The variability of a set of five repeated counts of a sample left in the dish and merely stirred up between replicate counts was determined and found to be significantly lower than that established for the counts after treatments (Nematodes: $\bar{X}=90 ;$ S. D. $=2.2$; $\mathrm{n}=5$. Harpacticoids: $\overline{\mathrm{X}}=89 ; \mathrm{S} . \mathrm{D} .=3.3 ; \mathrm{n}=5$ ). Errors due to omissions and double counts are therefore negligible, at least in the present context. However, the occurrence of detritus in the sample may change the situation completely.

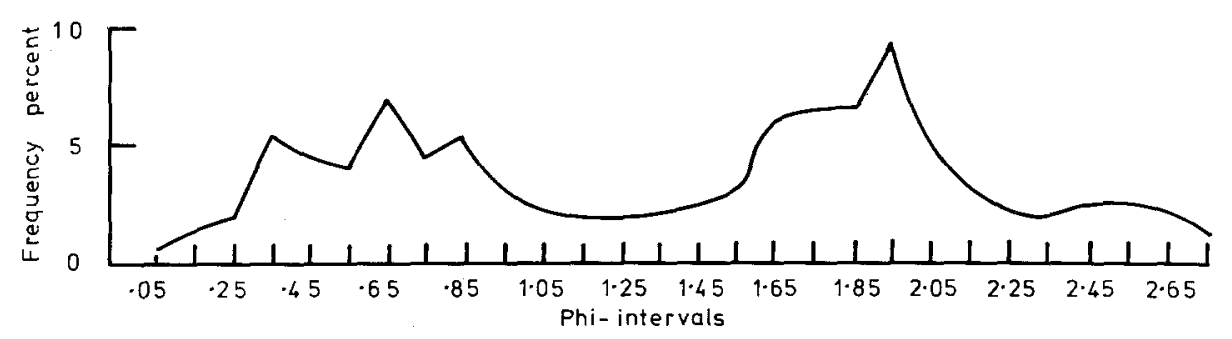

Fig. 2: Plot of grain size (Phi-intervals) against frequency percent for sediment B. Median $=0.849$, mean $=0.864$, sorting $=0.272$, skewness $=0.385$, kurtosis $=1.819$

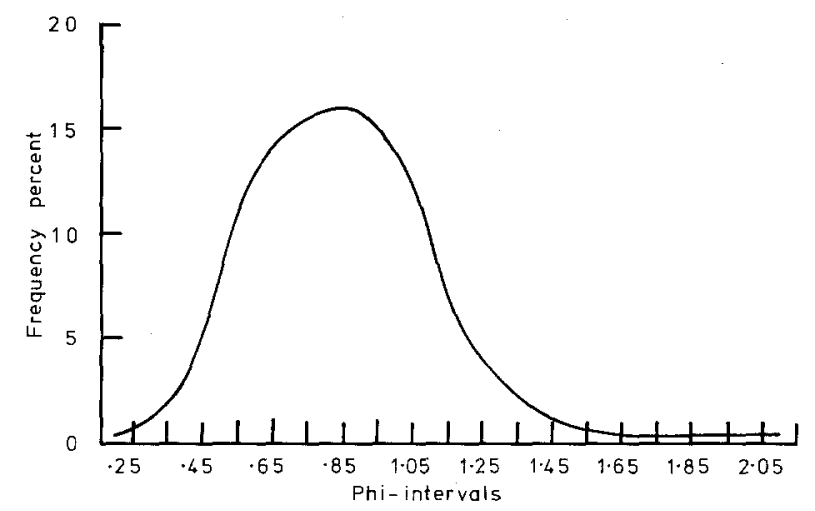

Fig. 3: Plot of grain size (Phi-intervals) against frequency percent for sediment A. Median = 1.549, mean $=1.383$, sorting $=0.711$, skewness $=-0.270$, kurtosis $=-1.217$

The data were subjected to $2 \times 2 \times 2$ factorial analysis (Snedecor \& Cochran, 1967; pp. 354-361) to separate the effects of methods, sand type and extraction medium. Nematodes and harpacticoids were analysed separately; the results are shown in Table 4. Nematodes did not give significant differences for any factors. Using the Oostenbrink apparatus, the number of harpacticoids recovered by extraction with sea water was, however, significantly lower than treatments with fresh water $(F=10.5 ; \mathrm{P}<0.05)$. As expected, the interaction of method and extraction medium was also highly significant $(\mathrm{F}=38.8 ; \mathrm{P}<0.01)$. 
A. H. Fricke
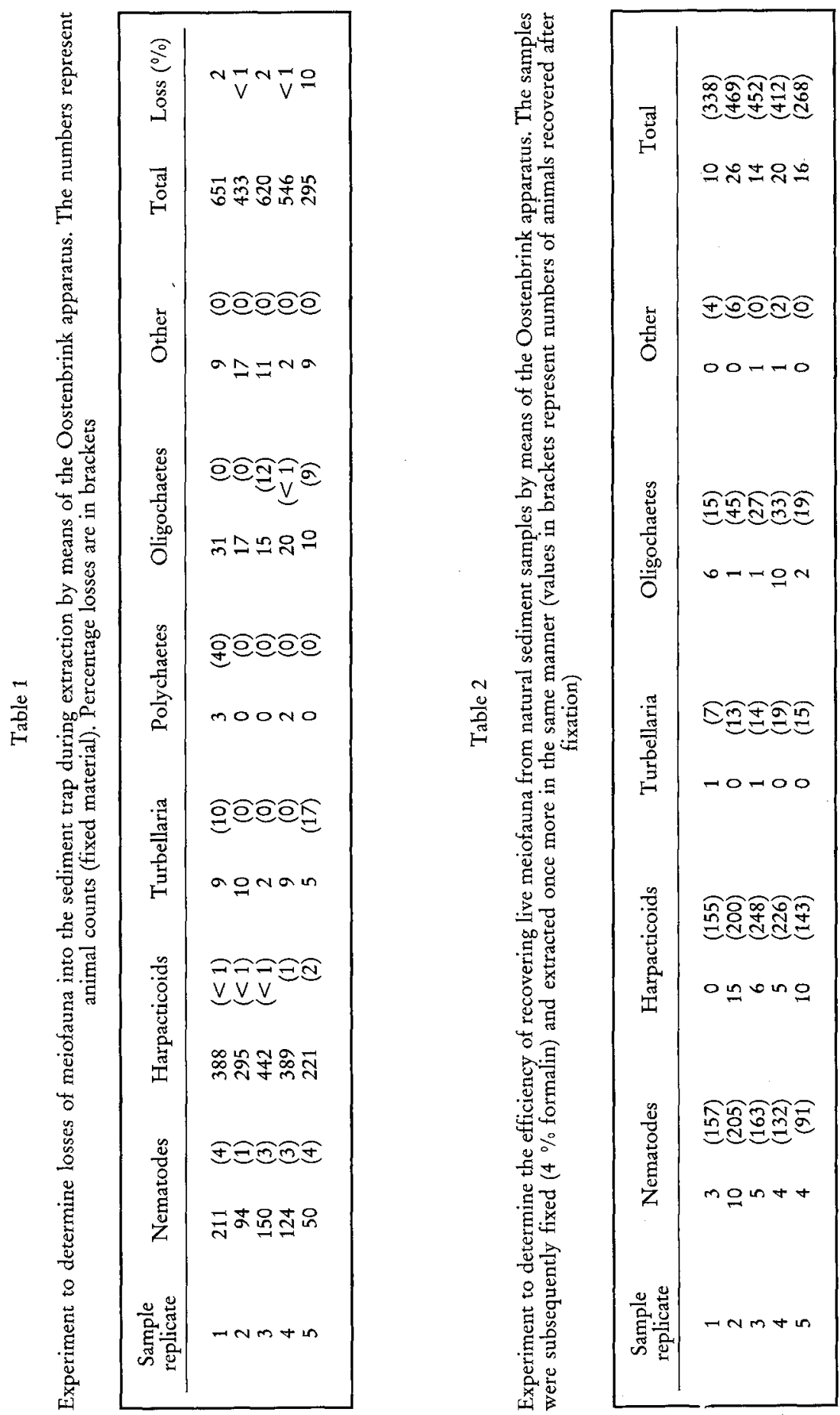
Meiofauna extraction efficiency
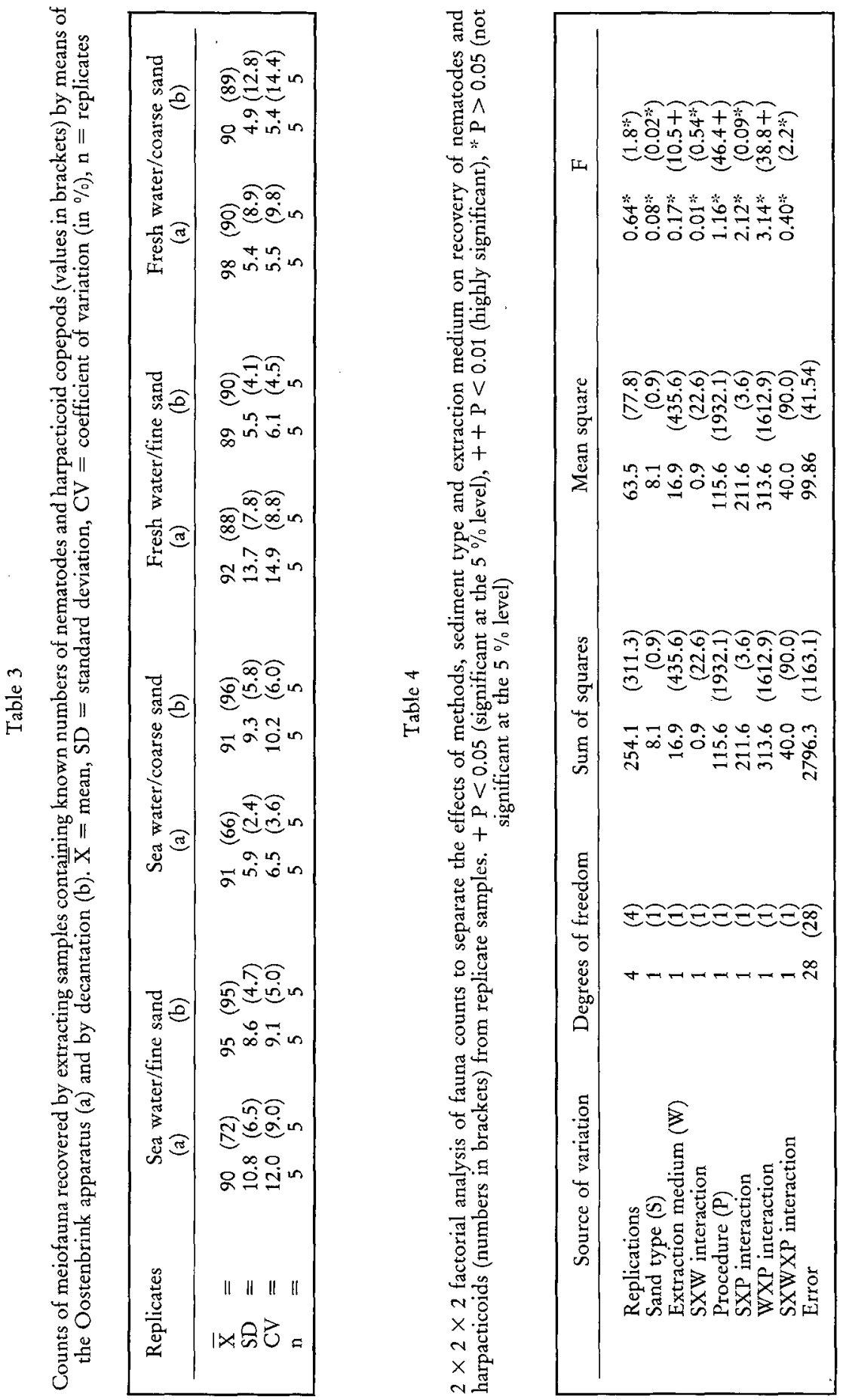


\section{DISCUSSION}

In having to choose between Oostenbrink's approach and Boisseau's modified method as used by Drzycimski, Gray and McIntyre (see Uhlig et al., 1973), we opted for the former for several reasons. The results obtained indicate that soft fauna is efficiently recovered by the Oostenbrink method but not by elutriation. The principle underlying the two methods is similar, namely making use of the difference in settling velocity between organisms and sediment. The extraction efficiency by the flotation method is furthermore flexible in lending itself to optimisation by adjusting the rate of water flow against sediment particle size in a calibration trial run. Making use of the different physical behaviour of settling particles is presently gaining increased favour and has proved to be a powerful tool in sediment analysis (Flemming \& Thum, 1978). Practically the Oostenbrink method is particularly convenient; it is reproducible in processing numerous samples and, furthermore, the apparatus is sturdy. The largely automatic elutriation method of Boisseau (1957) was not tested but may be suitable.

We were unable to demonstrate a difference in extraction efficiency between coarse and fine sands by the Oostenbrink method; in agreement with the findings described by Uhlig et al. (1973) especially mud samples were found to pose problems for rapid meiofauna extraction. We adopted the sugar gradient centrifugation of Heip et al. (1974) when such material had to be dealt with.

Fresh water as an alternate extraction medium was chosen for practical reasons since it is available everywhere. Tests showed that well fixed fauna are not dimensionally distorted by immersion in fresh water. The relatively lower recovery of harpacticoids was not expected. If anything, the higher density of sea water should increase the buoyancy of the copepods, thereby reducing losses by maintaining them in the water column for longer periods. It is well known that sea water has a higher surface tension than fresh water. One effect of this property is a tendency for particulate matter to plate out on hard surfaces. This could affect organisms with numerous appendages such as harpacticoids more than nematodes and thus lead to the difference observed in recovery. In view of the results obtained the use of fresh water may be preferred. Losses of fauna into the sediment trap were very low and cannot account for the consistent losses found for both taxa (Table 1). They remain unexplained.

We have used the flotation method for several years and obtained consistent results with different operators and a variety of sample types. The method is gentle, and the animals to be extracted generally are not damaged in contrast with decantation by which the fauna may suffer too vigorous stirring. Both methods take between 9 to 12 min; thus the time factor is similar.

Acknowledgements. My sincere thanks are extended to Ms F. le Clus of the Sea Fisheries Branch, Dept. of Industries for inspiring the statistical treatment and Mr. H. Hennig of the National Research Institute for Oceanology who performed the sediment analysis. This work was funded by the National Research Institute for Oceanology (NRIO/CSIR). 


\section{LITERATURE CITED}

Ankar, S. \& Elmgren, R., 1976. The benthic macro- and meiofauna of the Askö-Landsort area (northern Baltic proper). Contrib. Askö Lab. 11, 1-115.

Boisseau, J. P., 1957. Techniques pour l'étude quantitative de la faune interstitielle des sables. C.r. Congr. Socs sav. Paris Sect. Sci. 1957, 117-119.

Caveness, F. E. \& Jensen, H. J., 1955. Modification of the centrifugal flotation technique for the isolation and concentration of nematodes and their eggs from soil and plant tissue. Proc. helminth. Soc. Wash. 22, 87-89.

Cobb, N. A. 1924/1925. Removing nemas from soil by flotation. J. Parasit. 11, 103-105.

Dybern, B. I., Ackefors, H. \& Elmgren, R., 1976. Recommendations on methods for marine biological studies in the Baltic Sea. Baltic mar. Biol. Publs 1, 1-96.

Elmgren, R., 1976. Baltic benthos communities and the role of the meiofauna. Contr. Askö Lab. 14, $1-31$.

Flemming, B. W. \& Thum, A. B., 1978. The settling tube - a hydraulic method for the grain size analysis of sands. Kieler Meeresforsch., Sonderheft 4, 82-95.

Heip, C., Smal, N. \& Hautekiet, W., 1974. A rapid method of extracting meiobenthic nematodes and copepods from muds and detritus. Mar. Biol, 28, 79-81.

Oostenbrink, M., 1960. Estimating nematode populations by some selected methods. Nematology 6, $85-102$.

Snedecor, G. W. \& Cochran, W. G., 1967. Statistical methods. The Iowa State Univ. Press, Ames, Iowa, 354-361.

Uhlig, G., 1964. Eine einfache Methode zur Extraktion der vagilen mesopsammalen Mikrofauna. Helgoländer wiss. Meeresunters. 11, 178-185.

- Thiel, H. \& Gray, J. S., 1973. The quantitative separation of meiofauna. Helgoländer wiss. Meeresunters. 25, 173-195. 